\title{
MOLECULAR BASIS OF BETA THALASSEMIA MUTATIONS IN EGYPTIAN PATIENTS
}

\author{
Osama Shalaan $^{1}$, Ahmed Daif ${ }^{1 *}$, Khalil Elhalfawy ${ }^{2}$ \\ ${ }^{1}$ Molecular Diagnostics and Therapeutics Department, Genetic Engineering and \\ Biotechnology Research institute (GEBRI), University of Sadat City, Egypt \\ ${ }^{2}$ Molecular Biology Department, Genetic Engineering and Biotechnology \\ Research institute (GEBRI), University of Sadat City, Egypt
}

* To whom correspondence should be addressed: Molecular Diagnostics and Therapeutics Department, Genetic Engineering and Biotechnology Research institute (GEBRI), University of Sadat City, Egypt.

\begin{abstract}
Thalassemia is a wide range hereditary disease with high incidence in Egypt along with the high frequency of consanguineous marriages. Investigation the heterogeneity, molecular basis, and natural history are the most effective methods to deal with the thalassemia to develop effective method for management and prevention including the prenatal diagnosis. The current study aims to detect the most common $\beta$-globin gene mutations in Egypt among $\beta$-thalassemic patients by using PCR based reverse hybridization method (StripAssay) for the most prevalent $22 \beta$-globin gene mutations in the mediterranean population in an attempt to estimate the incidence of each mutation, and an attempt to improve our control strategy of $\beta$ thalassemia. This study included a total of 37 confirmed $\beta$ - thalassemia ethnic Egyptian patients ( 23 males and 14 females) out of them 17 patients were a thalassemia major and 20 were a thalassemia intermediate. Evaluation of $\beta$-thalassemia mutations revealed that, the presence of 9 different $\beta$-globin mutations. The most frequent mutation were IVS 1110[34\%], IVS 1-6(23.5\%), IVS 1-1(19\%), Codon 27[6.5\%], IVS 2-848[6.5\%], IVS 2$745[2.1 \%$ ] and IVS 2.1 [2.5\%], Codon 39[4\%]), and IVS 1.5 [1.5\%]. IVS 1-110[G>A] is the commonest homozygous mutation found in 6 out of 14 homozygous cases accounting for about $43 \%$ of homozygous mutations while, IVS $1-110[\mathrm{G}>\mathrm{A}] /$ IVS $1-6[\mathrm{~T}>\mathrm{C}]$ is the commonest heterozygous mutation found in 6 out of 23 heterozygous cases accounting for about $26 \%$ of heterozygous mutations . In conclusion, $\beta$-Globin Strip Assay is useful rapid screening method for $\beta$-globin gene mutations which can provide an insight into the detection of individual patients, to take the proper measurement, and thus could be used as a basis for genetic counseling and prenatal diagnosis.
\end{abstract}

Keywords: $\beta$-Thalassemia, mutations, $\beta$-Globin Strip Assay (reverse dot-blot PCR), Egyptian

\section{INTRODUCTION}

$\operatorname{Beta}(\beta)$-thalassemias are a group of genetic (autosomal recessive) blood disorders characterized by decreased or absent $\beta$-globin chain synthesis (1). High prevalence is present in developing countries whereas the health problem is prominent and shortage of the healthcare

delivery strategy. The highest incidences are reported in populations of
African descent, Mediterranean, MiddleEast, Transcaucasia, Central Asia, Indian and Cyprus (2). Therefore, a thalassemia prevention program in these countries is highly needed (3). The position of Egypt in the center of the Middle East and as in many Mediterranean countries, $\beta$ thalassemia in Egypt considered as a major public health problem (4). In Egypt, it was reported that out of 1.5 million births, there are around one thousand child suffering 
from $\beta$ - thalassemia major (5). Due to the limited resources of Egypt, its healthcare system is unable to deal properly with such a large number of sick babies. Therefore, community based prevention system must be that includes identification of carrier patients, genetic counseling and prenatal diagnosis (6-8). More than 200 mutations are detected to cause $\beta$-thalassemia, the information available concerning the underlying molecular defects in $\beta$ thalassemia has not yet been completed. (9). $\beta$-thalassemia mutations varies significantly among different geographical areas, there for The success of carrier screening and prenatal diagnosis depends on the information of prevalent mutations of such area (10-14).

Previously, it was reported that the human $\beta$-globin gene has been genotyped using several methods such as a denaturating gradient gel electrophoresis (15), and PCR, followed by restriction digestion (16). These methods take long time for diagnosis (17).

In present study, a reversehybridization assay was designed for the rapid and simultaneous screening of $22 \beta$ globin gene mutations in a single procedure, which give the advantage of accuracy, sensitivity, and applicability of assay useful for prenatal diagnosis.

\section{SUBJECTS AND METHODS \\ Subjects}

The study participants were among a group of attendants to the hematology clinic of Abulrish hospital, Cairo University, Egypt. They comprised males and females suffering from $\beta$-thalassemia disease. Diagnosis of $\beta$-thalassemia disease was based on history, clinical examination and hematological investigations. All investigations were done in accordance with the Cairo University, health and human Ethical Clearance Committee guidelines for clinical researches. After obtaining informed consent, all participants were questioned in regard to their personal and family medical histories.

\section{Methods}

All affected patients were clinically classified into thalassemia major and thalassemia intermediate by collecting their peripheral venous blood for complete hematological examination with consideration to; the age of disease onset, the age of first transfusion, frequency of blood transfusion, hepatosplenomegaly, facial and growth affection.

\section{$\boldsymbol{\beta}$-Globin stripassay}

Reverse dot-blot PCR was done using $\beta$-Globin StripAssay MED ${ }^{\mathrm{TM}}$, (ViennaLab Diagnostics GmbH, Gaudenzdorfer Gurtel, Vienna, Austria). First, DNA was extracted from peripheral blood leukocytes obtained from EDTA anti coagulated blood samples according to standard protocols and commercial kits. The isolated DNA was subjected to multiplex PCR amplification reaction using biotinylated primers. The resulted amplified $\beta$-globin products are then selectively hybridized to a test strip containing wild type and mutant oligonucleotide probes immobilized as parallel lines. The color of the Bound biotinylated sequences is then developed. The assay covers 22 mutations, characteristics for the Mediterranean area.

\section{Statistical analysis}

Statistical Package for Social Sciences (SPSS) computer program (version 19 windows) was used for data analysis as follows: quantitative variables Results are expressed as mean \pm standard deviation (SD) or number (\%). While the qualitative variables as number and percentage. $\mathrm{P}$ value $\leq 0.05$ was considered significant and $<0.001$ was considered highly significant.

\section{RESULTS AND DISCUSSION}

This study included a total of 37 ethnic Egyptian patients (23 males and 14 females) who were confirmed to have $\beta$ thalassemia. Out of the $\beta$-thalassemia, 17 patients were a thalassemia major and 20 
were a thalassemia intermediate. The range of the ages were from 3 to 10 years with a mean and SD of 5.6 2.1 years. Male patients account for $62 \%$ of the studied patients 14 male patients give a thalassemia major picture and 9 male patients had the thalassemia intermediate picture. Female

Hematological data of study subjects revealed that, there were significantly lower hemoglobin $(\mathrm{Hb})$, and significantly higher reticulocytes, platelets and white blood cells (WBCs) in patients with thalassemia major compared with patients with thalassemia intermedia. Moreover there were no significant differences between patients with thalassemia major and thalassemia intermedia as regard mean corpuscular volume (MCV) and mean corpuscular hemoglobin $(\mathrm{MCH})$ as shown in Table 2.

Evaluation of $\beta$-thalassemia mutations in 37 patients with 74 alleles revealed the presence of 9 different $\beta$ globin mutations. The most frequent mutation is IVS $1-110[\mathrm{G}>\mathrm{A}]$ which account for about $34 \%$ of the studied alleles followed by IVS 1-6(T-C) which represent about $23.5 \%$. While IVS 1-1(G-A) account for $19 \%$. Other less

frequent mutations as Codon $27[\mathrm{G}>\mathrm{T}]$ and IVS $2-848[\mathrm{C}>\mathrm{G}]$ presented by $6.5 \%$ for each mutation, IVS $2-745[\mathrm{C}>\mathrm{G}]$ and IVS $2.1[\mathrm{G}>\mathrm{A}]$ presented by $2.5 \%$ for each mutation, Codon $39[\mathrm{C}>\mathrm{T}]$ ) account for patients account for $38 \%$ of the studied patients 3 female patients give a thalassemia major picture and 11 female patients had the thalassemia intermediate picture, moreover the multiple physical and clinical examinations are shown in Table 1.

$4 \%$ and IVS $1.5[\mathrm{G}>\mathrm{C}]$ represented by $1.5 \%$ as shown in Fig. 1.

IVS $1-110[\mathrm{G}>\mathrm{A}]$ represents the most common homozygous mutations 6 out of 14 homozygous cases about $43 \%$. In compound heterozygous cases, IVS 1$110[\mathrm{G}>\mathrm{A}]$ also is the most common heterozygous mutation account for 13 out of 23 of our heterozygous cases representing about 56\%. Next IVS1-6 [T>C] represents the second common homozygous mutations 3 out of 14 homozygous cases about 21\%. In compound heterozygous cases, IVS 1-

$6[\mathrm{~T}>\mathrm{C}]$ is the second common compound heterozygous mutation present in 11 out of 23 of our heterozygous cases account for $47 \%$.Followed by IVS 1$1[\mathrm{G}>\mathrm{A}]$ which represents the second common homozygous mutations 3 out of 14 homozygous cases about $21 \%$. In compound heterozygous cases, IVS 1$1[\mathrm{G}>\mathrm{A}]$ occupy the third place in compound heterozygous mutations account for 8 out of 23 of compound heterozygous cases representing about $34 \%$ 

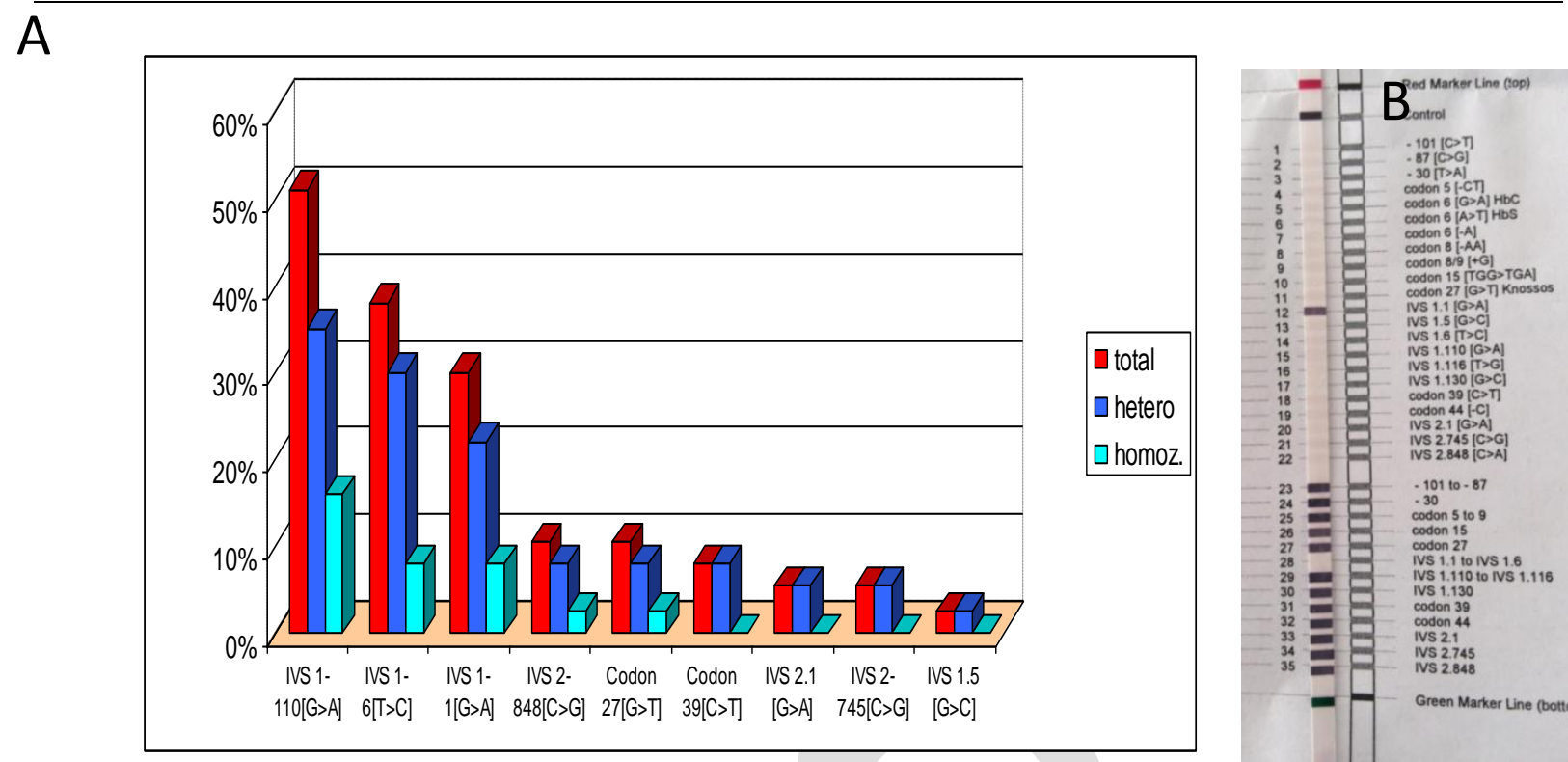

Fig 1. $\beta$-Globin gene mutations. (A) Diagram describes the distribution and frequency of $\beta$-thalassemia mutations among carrier patients. (B) Representative of the test strip used in the study

Beta Thalassemia is a group of hemoglobin diseases caused by a reduction $(b+)$ or abolish (b0) in the synthesis of $\beta$ globin chains. Carrier individuals can be either compound heterozygous, or homozygous for $\beta$-thalassemia [18].

$\beta$-Thalassemia is the most common genetically inherited $\beta$-globin disorder in Egypt.(19). Combined effects of high carrier rates and high frequency of consanguineous marriages make prevalence of $\beta$-thalassemia particularly high in Egypt (20).Up to date in Egypt, carrier detection and genetic counseling and carrier identification is essentially presented to families with an affected individual. In these families, the phenotypic and genotypic evaluation is usually performed in these families to determine the prognosis and to offer the comprehensive genetic counseling. For further reduce the incidence of new births of children with $\beta$-thalassemia (21.)

Despite efforts to develop a therapy or bone marrow transplantation for $\beta$ thalassemia, still the prenatal diagnosis followed by termination of the affected fetus remains the best form of prevention.
Until now, more than 200 different mutations have been described in patients with $\beta$-thalassemia. So the aim of this study is to find rapid, sensitive accurate method to detect the affected individuals, carrying the $\beta$-globin gene mutations and applicability of this method to use in prenatal diagnosis and further prevention of the disease.

In our studied, the commonest symptoms in the subjected patients were Pallor and jaundice while the most common signs werehepatomegaly and splenomegaly. This is in accordance with $(22,23)$.

In 37 patients with 74 alleles revealed the presence of 9 different $\beta$-globin mutations. The most frequent mutation is IVS 1-110[G>A] which accountfor about $34 \%$ of the studded alleles followed by IVS 1-6(T-C) which represent about $23.5 \%$. These results are in agreement with El Fadaly et al, 2015, El-Shanshory et al 2014, Elmezayen et al., 2014 and ElBeshlawy et al, 2012, (20, 22, 24- 25).

IVS $1-110[\mathrm{G}>\mathrm{A}]$ is the commonest homozygous mutation found in 6 out of 14 homozygous cases accounting for about $43 \%$ of homozygous mutations. IVS 1- 
$110[\mathrm{G}>\mathrm{A}] /$ IVS $1-6[\mathrm{~T}>\mathrm{C}]$ is the commonest heterozygous mutation found in 6 out of 23 heterozygous cases accounting for about $26 \%$ of heterozygous mutations. Our results are in agreement with the resultsof El-Beshlawy et al, 2012, and Jifri et al, 2010 (25- 26). On the other hand El -Gawhary et al., 2007 and Elmezayen et al., $2014(27,24)$ reported that IVSI-6 is more frequent than IVSI-110.

\section{CONCLUSION}

Knowledge of $\beta$-thalassemia mutations and their incidence may be a step in the heterogeneity detection of thalassemic carrier patients; Consequently, prenatal diagnosis in families at-risk can reduce the incidence and the severity of the disease and thus can provide an insight into the prevention strategy for this disease.

\section{Declaration of Interest:} interest

The authors report no conflicts of

\section{REFERENCES}

1. Bain BJ. The alpha, beta, delta and gamma thalassaemias and related conditions. In Haemoglobinopathy Diagnosis, 2nd Edition. Wiley-Blackwell. Oxford; 2006:63-138.

2. Weatherall DJ, Clegg JB, Higgs DR, Wood WG. The hemoglobinopathies. In:Scriver CR, Beaudet Al, Sly WS, Valle $\mathrm{D}$, Vogelstein B, editors. The metabolic and molecular bases of inherited disease (OMMBID). Chapter 101. New York, NY: McGraw-Hill, 2002. Available at: www.ommbid.com. AccessedDecember 31, 2007

3. Al-Allawi NA, Jubrael JM, Hughson M. Molecular characterization of betathalassemia in the Dohuk region of Iraq. Hemoglobin 2006; 30:479-486.

4. El-Beshlawy A, Kaddah N, Ragab L, Hussein I, Mouktar G, Moustafa A, El Raouf E, Hassaballa N, Gaafarand T, ElSendiony $\mathrm{H}$. Thalassemic prevalence and status in Egypt. Proceedings of the annual meeting of the American Pediatric Society, San Francisco, CA, USA, (1-4 may 1999); abstract 102 .
5. El-Hashemite N, Petrou M, Khalifa AS, et al. Identification of novel Asian Indian and Japanese mutations causing $\beta$ thalassemia in the Egyptian population. Hum Genet. 1997;99(2):271-274.

6. Ahmed S, Saleem M, Modell B, Petrou M. Screening extended families for genetic hemoglobin disorders in Pakistan. N Engl J Med. 2002;347:1162-1168.

7. Ahmed S. Prenatal diagnosis of $\beta$ thalassemia: 12 years' experience at a single laboratory in Pakistan. Prenatal Diag. 2007;27:1224-1227.

8. Naseem S, Ahmed S, Vahidy F. Impediments to prenatal diagnosis of beta thalassemia: experiences from Pakistan. Prenatal Diag. 2008;28:1116-1118.

9. Omar A, Abdel Karim E, El Gendy W, Marzouk I, Wagdy M (2005) Molecular basis of beta thalassemia in Egypt. Egypt $\mathbf{J}$ Immunol 12(1):15-24.

10. Colah R, Gorakshakar A, Nadkarni A, et al. Regional heterogeneity of B-thalassemia mutations in the multi ethnic Indian population. Blood Cells Mol Dis. 2009;42(3):241-246.

11. Edison ES, Shaji RV, Devi SG, et al. Analysis of $\beta$ globin mutations in the Indian population: presence of rare and novel mutations and region-wise heterogeneity. Clin Genet. 2008;73(4):331337.

12. Black ML, Sinha S, Agarwal S, et al. A descriptive profile of $\beta$-thalassemia mutations in India, Pakistan and Sri Lanka. J Commun Genet. 2010;1:149-157.

13. Başak AN. The molecular pathology of $\beta$-thalassemia in Turkey: The Boğazıçı University experience. Hemoglobin. 2007;31:233-241.

14. Akhavan-Niaki $\mathrm{H}$, Derakhshandeh-Peykar P, Banihashemi A, et al. A comprehensive molecular characterization of beta thalassemia in a highly heterogeneous population. Blood Cells Mol Dis. 2011;47:29-32.

15. Girodon E, Ghanem N, Vidaud M, Riou J, Martin J, Galacteros F, Goossens M. Rapid molecular characterization of mutations leading to 
unstable hemoglobin beta-chain variants. Ann Hematol 1992; 65:188-192.

16. Zhang YH, McCabe LL, Wilborn

M, Therrell BL Jr, McCabe ER. Application of molecular genetics in public health: improved follow-up in a neonatal hemoglobinopathy screening program. Biochem Med Metab Biol 1994; 27-35.

17. Herrmann MG, Dobrowolski SF, Wittwer CT. Rapid beta-globin genotyping by multiplexing probe melting temperature and color. Clin Chem 2000; 46:425-428.

18. Hussein G, Fawzy M, El-Serafi T et al (2007) Rapid detection of bthalassemia alleles in Egypt using naturally or amplified created restriction sites and direct sequencing: a step in disease control. Hemoglobin 31(1):49.

19. El-Beshlawy A and Youssry I. Prevention of hemoglobinopathies in Egypt. Hemoglobin 2009; 33 (1):14-20.

20. EL-Fadaly, A. Abd-Elhameed, E. Abd-Elbar, M. El-Shanshory. Accuracy of Reverse Dot-Blot PCR in Detection of Different b-Globin Gene Mutations. Indian J Hematol Blood Transfus 2015.

21. Barrai I, Vullo C. Assessment of prospective genetic counseling in the Ferrara area. Am J Med Genet 1980; 6(3):195-204.

22. Soliman HH, Kabbash IA, ElShanshory MR et al (2012) Evaluation of immune status against hepatitis $\mathrm{B}$ in children with thalassemia major in Egypt. JMID 2:44-49.

23. Galanello R, Barella S, Satta S, Maccioni L, Pintor C, Cao A. Homozygosity for nondeletion delta-beta(0) thalassemia resulting in a silent clinical phenotype. Blood 2002;100:1913-1914.

23. Cao A, Galanello R. Betathalassemia. Genet Med. 2010;12:61-76

24. El mezayen A. Kotb S, Ahmed M, et al. (2015): $\beta$-globin mutations in egyptian patients with $\beta$-thalassemia. LabMed. 46:8-13.

25. El-Beshlawy, A. El-Shekha, M. Momtaz, F. Said, M. Hamdy, O. Osman, S. Meshaal, T. Gafaar and M. Petrou (2012): Prenatal diagnosis for thalassaemia in Egypt: what changed parents'attitude. Prenatal Diagnosis 32,1-6.

26. Jiffri $\mathrm{E}$, Bogari $\mathrm{N}$, Zidan $\mathrm{K}$, et al.(2010): Molecular updating of $\beta$ thalassemia mutations in the upper Egyptian population. Hemoglobin, 34(6):538-547.

27. El-Gawhary S, El-Shafie S, Niazi M, et al. (2007): Study of $\beta$-thalassemia mutations using the polymerase chain reaction amplification refractory mutation system and direct DNA sequencing techniques in a group of Egyptian thalassemiapatients. Hemoglobin, 31: 6369. 